\title{
Removal of Chromium Hexavalent Using Agriculture Waste
}

\author{
Amnorzahira Amir, Raja Noraisar Raja Abd Rahim, and Suhaimi Abdul-Talib
}

\begin{abstract}
This study investigated the removal of chromium hexavalent $\left(\mathrm{Cr}^{6+}\right)$ using agriculture wastes. Experiments works were conducted under laboratory condition. $\mathrm{Cr}^{6+}$ was intensively used in industrial and manufacturing industries. Improper treatment of $\mathrm{Cr}^{6+}$ was lead to existing of $\mathrm{Cr}^{6+}$ in soil and groundwater. Tea waste (TW), coconut shell (CS) and orange peel $(\mathrm{OP})$ were selected as an adsorbent to remove $\mathrm{Cr}^{6+}$ in this study. Characterization study on the surface morphology of TW, CS and OP was conducted using Scanning Electron Morphology (SEM), Fourier-Transfer Infrared (FTIR), and PH REdox Equilibrium (PHREEQC) software. Surface morphology of TW was significantly different compared to CS and OP. Surface morphology of TW was fully covered by wide pores and provided high reactive surface area. Surface morphology of CS and OP contained less pores compared to TW and demonstrated different type roughness. FTIR analysis revealed that TW, CS and OP contained similar chemical functional groups which were carboxyl group $(\mathrm{C}=\mathrm{O}, \mathrm{C}-\mathrm{O})$ and bonded-OH. Adsorption of $\mathrm{Cr}^{6+}$ on the surface of TW, CS and $O P$ can be described by Freundlich isotherms. PHREEQC analysis demonstrated potential reaction mechanisms that may involve in this system were adsorption and complexation. Removal kinetics for $\mathrm{Cr}^{6+}$ using $\mathrm{TW}, \mathrm{CS}$ and OP was measured at neutral pH under anaerobic condition using Atomic Absorption Spectroscopy (AAS). Removal of $\mathrm{Cr}^{6+}$ using TW was the highest compared to $\mathrm{CS}$ and $\mathrm{OP}$ in 30 mins $\left(k_{\mathrm{TW}}>k_{\mathrm{CS}}>k_{\mathrm{OP}}\right)$. Removal kinetic rate of $\mathrm{Cr}^{6+}$ using $\mathrm{TW}, \mathrm{CS}$ and OP was well fitted to pseudo-first-order kinetic. This study provides significant knowledge on the potential of TW as an economic and excellent bioadsorbent for removal of heavy metals in soil and groundwater.
\end{abstract}

Index Terms-Adsorption, agriculture waste, chromium hexavalent, removal kinetic.

\section{INTRODUCTION}

Toxic heavy metals are abundantly present in soil and groundwater due to extensive usage of heavy metals in industrial and manufacturing activities such as smelting and mining, electroplating, leather manufacturing and tanning [1], [2]. Chromium hexavalent $\left(\mathrm{Cr}^{6+}\right)$ has been reported as the most predominant heavy metal found in soil and groundwater and it is very toxic and harmful to human. Previous studies have reported that $\mathrm{Cr}^{6+}$ caused chronic and carcinogenic diseases such as skin cancer, lung cancer and kidney damage [3]. However, fate of $\mathrm{Cr}^{6+}$ in soil and groundwater remained unclear.

Intensive remediation studies on the removal of heavy metals using a variety of adsorbents have been reported. For

Manuscript received September 2, 2016; revised November 11, 2016.

The authors are with Universiti Teknologi MARA, Malaysia (e-mail: amnorzahira@salam.uitm.edu.my, ecsuhaimi@salam.uitm.edu.my). example removal of $\mathrm{Cr}^{6+}$ using iron-bearing soil minerals, e.g., nano zero valent iron and magnetite [4], [5] and commercial adsorbents, e.g., silica gel, activated alumina, zeolites and activated carbon [6]. These studies revealed that reactive functional groups (e.g., $-\mathrm{OH}, \mathrm{C}=\mathrm{O}$ and $\mathrm{N}-\mathrm{H}$ ) on the surface of adsorbents play important role on the removal of heavy metals. However, preparations of these adsorbents were complicated and adsorbent surface reactivity may decrease due to uncontrolled ions complexation with other cations [7]. Previous study also reported that an addition of chemicals (e.g., commercial polymer) into soil and groundwater may contaminate the environment [8]. Due to these limitations, agriculture waste has been used as adsorbent to remove heavy metals in soil and groundwater.

Literatures have reported that agriculture wastes (e.g., tea waste, leaves of date trees and walnut shell) were used as an adsorbent to remove heavy metals in surface water [7], [9], [10]. Recently, agriculture wastes have gain greater attention due to many obvious advantages such as easy availability, comparable efficiency, resource generation, pollution abatement, and low cost adsorbent [6], [7]. There are a lot of agriculture wastes in Malaysia such as tea waste (TW), coconut shell (CS) and orange peel (OP) that are abundantly and readily available. However, studies on the removal of heavy metals by TW, CS and OP were limited and focus only on removal rate of heavy metals. Scientific study on the potential reaction mechanisms during the removal process was not reported in detail.

In this study, we elucidated the role of agriculture wastes as an adsorbent and characterized the removal kinetic of heavy metals using agriculture wastes. TW, CS and OP were selected as an adsorbent and $\mathrm{Cr}^{6+}$ as a representative target heavy metal. To fulfil the goals of this study, (1) characterization study on the surface morphology of TW, CS and $\mathrm{OP}$ was investigated, (2) the functional groups for $\mathrm{Cr}^{6+}$ sorption and potential reaction mechanisms were identified and (3) removal kinetic of $\mathrm{Cr}^{6+}$ using TW, CS and OP were monitored.

\section{Procedures}

\section{A. List of Chemicals}

Raw material and chemicals utilized for this study include agriculture wastes (TW, CS, and OP), Hydrochloric acid (HCl) $(96 \%, \mathrm{R} \& \mathrm{M})$, Sodium hydroxide $(\mathrm{NaOH})(98.86 \%$, Fisher Scientific), and Potassium dichromate $\left(\mathrm{K}_{2} \mathrm{Cr}_{2} \mathrm{O}_{7}\right)$ $(99.99 \%$, Merck). Deaerated deionized water (DDW) prepared using ultra pure water $(18 \Omega . \mathrm{cm})$ purged with $\mathrm{N}_{2}$. Anaerobic chamber was maintained by purging with $95 \% \mathrm{~N}_{2}$ 
and $5 \% \mathrm{H}_{2}$. All reagents and solutions used in the experiments were prepared using DDW.

\section{B. Collection and Preparation of Agriculture Wastes}

TW, CS and OP were selected as agriculture wastes in this study. TW was collected from the tea factory namely Boh Plantation Sdn.Bhd at Cameron Highland, Malaysia. CS and OP were collected from the Shah Alam Market, Section 16, Shah Alam. The collected wastes were washed and dried for 48 hours at $60^{\circ} \mathrm{C}$. After drying, the wastes were ground using a household simple mixer grinder to fine powder. Average size of the resulting powder was $250 \mu \mathrm{m}$.

\section{Experimental and Analytical Procedures}

All samples and experimental works were prepared and conducted under anaerobic condition. For characterization study of agriculture wastes, ground samples (1g) were transferred into amble vials $(42 \mathrm{~mL})$ and subjected to Scanning Electron Micrographs (SEM) and Fourier-Transfer Infrared (FTIR) analysis. For adsorption experiments, 0.5, $1.0,1.5,2.0,2.5,7.0$ and $10.0 \mathrm{~g}$ of agriculture wastes were weighted and transferred into amber vials. Solution at $\mathrm{pH} 7$ was prepared using $0.1 \mathrm{~N} \mathrm{HCl}$ and $0.1 \mathrm{~N} \mathrm{NaOH}$. Three (3) ppm of $\mathrm{K}_{2} \mathrm{Cr}_{2} \mathrm{O}_{7}$ was prepared with DDW containing solution at $\mathrm{pH} 7$ and transferred into vials. Samples were mixed and equilibrated by a rotator for 10 mins. Concentrations of aliquots were measured using Atomic Absorption Spectroscopy (AAS). Batch experiment was performed to monitor removal kinetic of $\mathrm{Cr}^{6+}$ using agriculture wastes (TW, $\mathrm{CS}$ and OP). An approximate $0.01 \mathrm{~g}$ of TW, CS and OP were transferred into amble vials. Three (3) ppm of $\mathrm{Cr}^{6+}$ was prepared with DDW containing solution at $\mathrm{pH} 7$ and poured into the vials. Samples were mixed and equilibrated by a rotator for different reaction times and the concentrations of aliquot were measured using AAS.

For characterization of agriculture waste, SEM analysis was conducted to determine the surface morphology of the TW, CS and OP. SEM was set up with LFD detection (Quanta FEG 450) with $10 \mathrm{kV}$ voltage and magnification of $50,000 x$ and 100,000x, respectively. Sample of agriculture wastes were carefully packed under anaerobic condition to avoid any reaction with oxygen. The samples were vacuumed for $5 \mathrm{~min}$ to avoid interference between gas molecules and electron beam, which was used for imaging to enhance resulting images. Concentration of $\mathrm{Cr}^{6+}$ was determined using AAS equipped with hollow cathode lamps, flame burner head and a mono-chromator. Air-acetylene flame was used at $2300^{\circ} \mathrm{C}$. $\mathrm{Cr}^{6+}$ can be detected at wavelength $357.9 \mathrm{~nm}$. AAS was calibrated using a standard concentration of $0.1,0.5,1.0$ and $1.5 \mathrm{mg} / \mathrm{L}$ of $\mathrm{Cr}^{6+}$. The optimum detection range for this method is $0.02 \mathrm{mg} / \mathrm{L}$ to $200 \mathrm{mg} / \mathrm{L}$.

Chemical speciation analysis of $\mathrm{Cr}^{6+}$ was determined using PH REdox Equilibrium (PHREEQC) software. PHREEQC is computer program for speciation, batch-reaction, one-dimensional transport, and inverse geochemical calculations. It uses $\mathrm{C}$ and $\mathrm{C}++$ programming languages that is designed to perform a wide variety of aqueous geochemical calculation. PHREEQC can be used to identify potential chemical species occur before and after reaction between surface chemical functional group on the surface of adsorbent and metals. Input data will be obtained from experimental work and FTIR analysis. Output from PHREEQC may give suggestion on the potential reaction mechanisms that occurred during adsorption process such as redox, complexation and precipitation.

\section{RESULTS AND DISCUSSION}

\section{A. Characterization study of agriculture waste}

Figs. 1a through 1c show the surface morphology of TW, $\mathrm{CS}$ and OP at neutral $\mathrm{pH}$. SEM images clearly demonstrate that the surface morphology of TW, CS and OP were significantly different. Figure 1a clearly shows that TW contains large number of wide pores in its external region. Surface morphology of TW in this study was similar to surface morphology of TW collected from tea plant located in Huangshan, China [7]. Figure 1b and 1c show surface morphology of CS and OP contain fewer pores compared to TW, and surface of CS has several layers and less rough compared to OP. Literature suggests that the rough surface and widely distributed pores can offer greater surface area and more binding sites for metal [7]. This result suggests that different type of surface morphology of TW, CS and OP may significantly contribute to different removal kinetic of $\mathrm{Cr}^{6+}$.

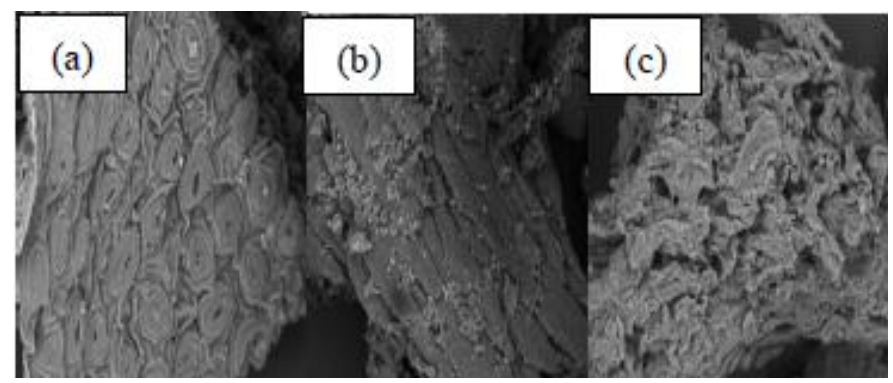

Fig. 1. SEM images of agriculture wastes at $\mathrm{pH} 7($ scale : $100 \mu \mathrm{m})$ : (a) TW, (b) CS and (3) OP

\section{B. Chemical Speciation Analysis}

Table I shows FTIR spectral characteristic analysis of TW, CS and OP. This analysis shows that these wastes have similar chemical functional group on their surfaces. Chemical functional group of carbon-oxygen single (C-O, carboxyl) (wavelength: 1015-1240 $\mathrm{cm}^{-1}$ ) and oxygen hydrogen (bonded-OH, hydroxyl) (wavelength: 2500-3350 $\mathrm{cm}^{-1}$ ) were observed on these agriculture wastes. However, chemical functional group of carbon-oxygen double $(\mathrm{C}=\mathrm{O}$; carboxyl) (wavelength $1711.14 \mathrm{~cm}^{-1}$ ) can only be observed on the surface of CS. This result indicates that ion exchange mechanisms of $\mathrm{C}-\mathrm{O}$ stretching (carboxyl), $\mathrm{C}=\mathrm{O}$ stretching (carboxyl) and bonded-OH (hydroxyl) groups provide predominant sorption sites for $\mathrm{Cr}^{6+}$ binding. Literature suggests that ion exchange mechanisms between metal $\left(\mathrm{M}^{2+}\right)$ and bonded- $\mathrm{OH}\left(\mathrm{R}-(\mathrm{OH})_{2} ; \mathrm{R}=\right.$ carbon-carbon stretch) on the surface of agriculture wastes probably the main reaction mechanism because bonded-OH is a stronger nucleophile compared to carboxyl group [11]. The ion exchange mechanism between $\mathrm{Cr}^{6+}$ and bonded-OH can be presented as equation 1 [7], [11].

$$
\mathrm{R}-(\mathrm{OH})_{2}+\mathrm{M}^{2+} \leftrightarrow-\mathrm{R}-(\mathrm{O})_{2}-\mathrm{M}+2 \mathrm{H}^{+}
$$


TABLE I: FTIR SPECTRAL CHARACTERISTIC OF TW, CS AND OP BEFORE REMOVAL REACTION

\begin{tabular}{|c|c|c|c|}
\hline $\begin{array}{l}\text { Chemical Functional } \\
\text { groups }\end{array}$ & $\begin{array}{c}\text { Standard } \\
\text { Range of } \\
\text { Wavelength } \\
\left(\mathrm{cm}^{-1}\right)\end{array}$ & $\begin{array}{c}\text { Actual } \\
\text { Wavelength } \\
\left(\mathrm{cm}^{-1}\right)\end{array}$ & $\begin{array}{c}\text { Type of } \\
\text { agriculture } \\
\text { wastes }\end{array}$ \\
\hline $\begin{array}{l}\text { Carbon-oxygen single } \\
\text { C-O }\end{array}$ & $1000-1300$ & 1028.68 & \multirow{2}{*}{ TW } \\
\hline $\begin{array}{l}\text { Oxygen hydrogen } \\
\text { O-H }\end{array}$ & $2500-3300$ & 3250.30 & \\
\hline $\begin{array}{l}\text { Carbon-oxygen single } \\
\text { C-O }\end{array}$ & $1000-1300$ & $\begin{array}{l}1031.52 \\
1239.42\end{array}$ & \multirow{3}{*}{ CS } \\
\hline $\begin{array}{l}\text { Carbon-oxygen } \\
\text { Double } \mathrm{C}=\mathrm{O}\end{array}$ & $1680-1750$ & 1711.14 & \\
\hline $\begin{array}{l}\text { Oxygen hydrogen } \\
\text { O-H }\end{array}$ & $2500-3350$ & 3347.63 & \\
\hline $\begin{array}{l}\text { Carbon-oxygen single } \\
\text { C-O }\end{array}$ & $1000-1300$ & $\begin{array}{l}1015.67 \\
1276.88\end{array}$ & \multirow[b]{2}{*}{ OP } \\
\hline $\begin{array}{l}\text { Oxygen hydrogen } \\
\text { O-H }\end{array}$ & $2500-3350$ & 3286.21 & \\
\hline
\end{tabular}

Fig. 2 shows the concentration of adsorbed $\mathrm{Cr}^{6+}$ on the surface of TW, CS and OP at pH 7 in 10 mins. Results significantly show that TW has high capacity to adsorb $\mathrm{Cr}^{6+}$ compared to CS and OP. The sorption isotherm of $\mathrm{Cr}^{6+}$ on the surface of TW, CS and OP fitted well with Freundlich isotherm. TW has the ability to adsorb $\mathrm{Cr}^{6+}$ at approximately $50 \%$ more than the CS and OP, indicating that TW has greater metal-ion binding capacity compared to CS and OP. This result suggests that TW may provide higher reactive surface area to enhance ion-exchange mechanism of the hydroxyl (bonded-OH) and carboxyl groups $(\mathrm{C}=\mathrm{O}, \mathrm{C}-\mathrm{O})$ with $\mathrm{Cr}^{6+}$ compared to $\mathrm{CS}$ and OP. PHREEQC analysis also shows $\mathrm{Cr} 6+$ reaction with bonded-OH via complexation. Several chemical species of $\mathrm{Cr}^{6+}$ with bonded-OH were identified (e.g., $\mathrm{Cr}(\mathrm{OH})_{6}$ and $\mathrm{Cr}(\mathrm{OH})_{3}$ ). This result suggests that equation 1 significantly represent the complexation reaction mechanism and Freundlich isotherm that may be occurred in this system. Previous study has also reported that bonded-OH on the surface of TW formed complexation with copper (II) [7]. Theoretically bonded-OH is a strong nucleophile and it significantly form complexation with heavy metals [11].

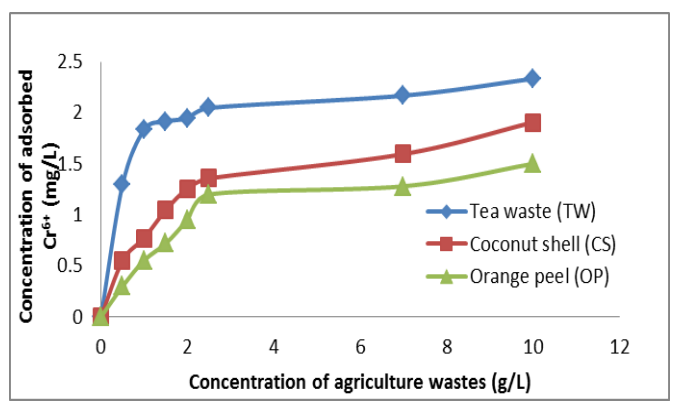

Fig. 2. Concentration of adsorbed $\mathrm{Cr}^{6+}$ on the surface of TW, CS and OP at $\mathrm{pH} 7$.

\section{Removal Kinetic of $\mathrm{Cr}^{6+}$ Using Agriculture Wastes}

Fig. 3 shows removal kinetics of $\mathrm{Cr}^{6+}$ using TW, CS and $\mathrm{OP}$ at neutral $\mathrm{pH}$ under anaerobic condition. The kinetic data of $\mathrm{Cr}^{6+}$ removal using several agriculture wastes were fitted by a pseudo-first-order kinetic model $\left(R^{2}=0.97\right)$. Removal kinetic of $\mathrm{Cr}^{6+}$ using TW $\left(k_{\mathrm{TW}}=0.814\right.$ min-1) was 18 times and 10.3 times greater than that using CS $\left(k_{\mathrm{CS}}=0.045 \mathrm{~min}^{-1}\right)$ and $\mathrm{OP}\left(k_{\mathrm{OP}}=0.079 \mathrm{~min}^{-1}\right)$ respectively in $30 \mathrm{mins}$. Approximately $95 \%$ of $\mathrm{Cr}^{6+}$ was removed by $\mathrm{TW}$, while $44 \%$ and $10 \%$ of $\mathrm{Cr}^{6+}$ were removed by $\mathrm{CS}$ and OP respectively in 10 mins. Furthermore, removal kinetics of $\mathrm{Cr}^{6+}$ using CS and OP were slow until to the end of sampling time. Experimental results indicate that different types of agriculture wastes have significantly different kinetic reactivity as adsorbent for heavy metal removal. Based on the FTIR analysis, C-O stretching (carboxyl) and bonded-OH were present on the surface of TW, CS and OP and these chemical functional groups play significant role on the removal of $\mathrm{Cr}^{6+}$. Previous study has reported that chemical functional groups such as bonded-OH and carboxyl group $(\mathrm{C}=\mathrm{O})$ were present on the surface of TW and they reacted reactively with heavy metals in aqueous phase [7]. Even though CS and OP also contained similar chemical functional groups, removal kinetic of $\mathrm{Cr}^{6+}$ by these agriculture wastes was significantly lower compared to removal kinetic of $\mathrm{Cr}^{6+}$ by $\mathrm{TW}$. This is due to the unique surface morphology of TW that was rough and contained of large number of wide pores. This study provides significant evidence that surface morphology of adsorbent also plays significant role on the removal of heavy metal at neutral $\mathrm{pH}$. This constitute a breakthrough on no previous reports had come to this finding.

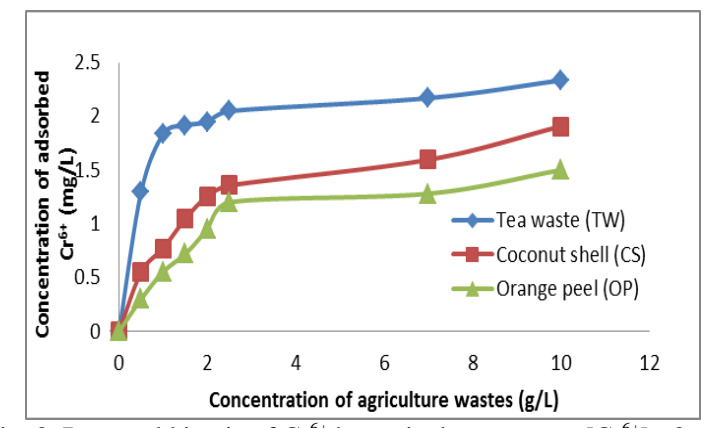

Fig. 3. Removal kinetic of $\mathrm{Cr}^{6+}$ by agriculture wastes. $\left[\mathrm{Cr}^{6+}\right]=3 \mathrm{ppm}$, [agriculture waste (TW, CS and OP)] $=0.01 \mathrm{~g}, \mathrm{pH}=7$.

\section{CONCLUSION}

This study investigated role of agriculture wastes as an effective adsorbent to remove $\mathrm{Cr}^{6+}$ in soil and groundwater. TW was identified as the most effective adsorbent to remove $\mathrm{Cr}^{6+}$ at neutral $\mathrm{pH}$. Characterization study of surface of TW, CS and OP shows that TW has unique surface morphology. Surface morphology of TW was fully covered by wide pores and provided high reactive surface area to allow ion-exchange mechanism of the bonded-OH and carboxyl group $(\mathrm{C}=\mathrm{O}, \mathrm{C}-\mathrm{O})$ with $\mathrm{Cr}^{6+}$. Surface morphology of $\mathrm{CS}$ and OP were rough and contain less pores. Adsorption of $\mathrm{Cr}^{6+}$ on the surface of TW was at approximately $50 \%$ higher compared to CS and OP in 10 mins. Adsorption of $\mathrm{Cr}^{6+}$ on the surface of TW, CS and OP can be described by Freundlich isotherms. PHREEQC analysis demonstrates potential reaction mechanisms that may involve in this system were adsorption and complexation. Removal kinetic of $\mathrm{Cr}^{6+}$ using TW was the highest compared to CS and OP in 30 mins $\left(k_{\mathrm{TW}}>k_{\mathrm{CS}}>k_{\mathrm{OP}}\right)$. This study also reveals that surface morphology of adsorbent plays an important role to enhance removal kinetic of $\mathrm{Cr}^{6+}$ even though carboxyl group $(\mathrm{C}=\mathrm{O}$, 
$\mathrm{C}-\mathrm{O}$ ) and bonded-OH were predominant chemical functional groups that were present on the surface of TW, CS and OP. This constitutes a novel finding which has not been previously reported. This study provides significant finding on the potential natural bioadsorbent TW as a commercial adsorbent to remove heavy metal in soil and groundwater. However, further study need to be conducted to identify optimum condition to enhance removal of $\mathrm{Cr}^{6+}$ using TW and additional parameters (e.g., electrolytes, microorganisms, and $\mathrm{pH}$ ) need to be investigated before real application of TW as an adsorbent at contaminated site.

\section{ACKNOWLEDGMENT}

This study was funded by Ministry of Education (MOE) through the Research Acculturation Grant Scheme (RAGS/1/2014/SG01/UiTM). Authors acknowledge the support from Faculty of Civil Engineering, Universiti Teknologi MARA Shah Alam.

\section{REFERENCES}

[1] A. Malik, "Simultaneous bioaccumulation of multiple metals from electroplating effluent using aspergillus lentulus," Water Res., vol. 46, p. 4997, 2012.

[2] A. Basu and T. M. Johnson, "Determination of hexavalent chromium reducing using $\mathrm{Cr}$ isotops : Isotopic fractionation factors for permeable reactive barrier materials," Environmental Science and Technology, vol. 46, pp. 5353-5360, 2012

[3] M. A. Barakat, "New trends in removing heavy metals from industrial wastewater," Arabian Journal of Chemistry, vol. 4, pp. 361-377, 2010

[4] N. N. L. Redzauddin, J. Kassim, and A. Amir, "Removal of zinc by nano-scale zero valent iron in groundwater," Applied Mechanics and Materials, pp. 773-774, 1231-1236, 2015.

[5] M. I. I. Amin, J. Kassim, and A. Amir, "Removal of Hexavalent Chromium by nano-scale zero valent iron in surface water," Desalination and Water Treatment Journal, 2015.

[6] A. Bhatnagar and M. Sillapää, "Utilization of agro-industrial and municipal waste materials as potential adsorbents for water treatment-A review," J. Chemical. Engineeing, vol. 157, pp. 277-293, 2010.

[7] S. Wan, Z. Ma, Y. Xue, M. Ma, S. Xu, and L. Qian, "Sorption of lead(II), cadmium (II), and copper(II) ions from aqueous solution using tea waste," Industrial and Engineering Chemistry Research, vol. 53, pp. 3629-3635, 2014.

[8] A. Amir and W. Lee, "Enhanced reductive dechlorination of tetrachloroethene by mackinawite with cobalamin (III)," Journal of Hazardous Material, pp. 235-236, 359-366, 2012.

[9] T. Altun and E. Pehlivan, "Removal of $\mathrm{Cr}(\mathrm{VI})$ from aqueous solutions by modified walnut shells,"Food Chem, vol. 132, p. 693, 2012.

[10] F. Boudrahem, F. Aissani-Benissad, and A. Soulah, "Sorption of lead (II) from aqueous solution by using leaves of date trees as an adsorbent," J. Chem. Eng. Data, vol. 56, pp. 1804, 2011.

[11] R. Schwarzenbach, P. M. Gschwend, and D. M. Imboden, Environmental Organic Chemistry, 2nd ed., New York: John Wiley \& Sons, 2003.

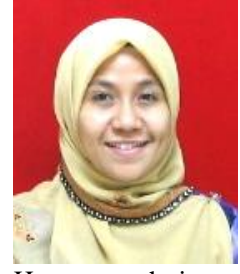

Amnorzahira Amir was born in Penang, Malaysia on March 11, 1980. In 2003, she obtained her B.E (CIVIL) (Hons) from the Universiti of Malaya, Malaysia. In 2007, she obtained an M.Sc in environmental engineering from Universiti of Putra, Malaysia and subsequently her $\mathrm{PhD}$ in civil and environmental engineering from Korea Advanced Institute of Science and Technology (KAIST) in 2012. Her research interests include air pollution assessment, degradation of organic and inorganic contaminants using abiotic and abiotic-biotic interaction processes in soil and groundwater. Currently her work focuses on degradation of polyromantic hydrocarbons (PAHs) using bacteria in wastewater, degradation of heavy metals using agriculture wastes and heavy metal mobilization in groundwater. She joined Universiti Technology MARA (UiTM) in 2012 and currently is a Senior Lecturer in Faculty of Civil Engineering, UiTM. Dr. Amnorzahira Amir is a professional member of Engineering Board of Malaysia (BEM). She was a project management engineer in consultant and contractor engineering firms in 2004 to 2005 . She has published her research findings in various ISI and SCOPUS indexed journals including Chemical Engineering Journal, Journal of Hazardous Materials, Industrial \& Engineering Chemistry Research Journal, international and local proceedings to name a few.

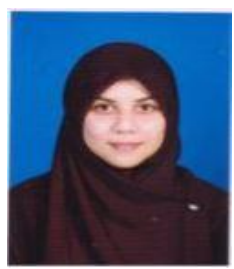

Raja Noraisar Raja Abdul Rahim was the University Malaysia Perlis (UniMAP). In 2015, she obtained her master of science in environmental engineering from the Universiti Technology MARA (UiTM). She was appointed as a research assistant in myBiorec laboratory, Faculty of Civil Engineering, UiTM and her research work was focus on removal of heavy metals using agricultural wastes in soil and groundwater. Currently she is working as lecturer in one of the private college in Kuala Lumpur.

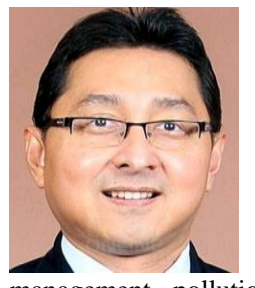

Suhaimi Abdul Talib was born in Perlis, Malaysia on August 31, 1964. In 1986, he obtained his B.E (CIVIL) (Hons) from the University of Melbourne, Australia. 1n 1996, he obtained an M.Sc in water and environment management from Loughborough University, U.K. and subsequently his $\mathrm{PhD}$ from Universiti Teknologi Malaysia in 2002. His research interests include in-sewer processes, environmenta management, pollution control and bioremediation. Currently his work focuses microbial transformation, bioremediation and the development on sustainable treatment technologies. He joined Universiti Technology MARA (UiTM) in 1988 and currently is Professor in Faculty of Civil Engineering, UiTM. Since October 2011, he has been entrusted by the university to serve as the Assistant Vice Chancellor of Development, Facilities Management and ICT of UiTM. Prof. Sr. Ir. Dr. Suhaimi Abdul Talib is a professional member of both Engineering Board of Malaysia (BEM) and Institute of Surveyor Malaysia (MISM), as well as a corporate member of Institute of Engineers Malaysia (MIEM). An advocate of multidisciplinary of research, he has published his research findings in various ISI and SCOPUS indexed journals including Water Science Technology, Korean Journal of Chemical Engineering, Research Journal of Chemistry and Environment to name a few. 